\title{
FRICTIONAL SOUND ANALYSIS BY SIMULATING THE HUMAN ARM MOVEMENT
}

\author{
Khaldon Yosouf', Hadj Latroch', Laurence Schacher'1, Dominique C. Adolphe1, Emilie Drean', Véronique Zimpfer² \\ ${ }^{1}$ Université de Haute-Alsace - ENSISA-Laboratoire de Physique et Mécanique Textiles EA4365 /UHA 11, rue Alfred Werner 68093 Mulhouse CEDEX - \\ FRANCE. \\ ${ }^{2}$ Institut Franco-Allemand de Recherche de Saint Louis 5 rue du Général Cassagnou68301 Saint -Louis CEDEX - FRANCE \\ Tél : +33(0) 3893363 20, Fax : +33(0) 389336339 \\ E-mail : khaldon.yosouf@uha.fr, Laurence.schacher@uha.fr, dominque.adolphe@uha.fr.
}

\begin{abstract}
:
Fabric noise generated by fabric-to-fabric friction is considered as one of the auditory disturbances that can have an impact on the quality of some textile products. For this reason, an instrument has been developed to analyse this phenomenon. The instrument is designed to simulate the relative movement of a human arm when walking. In order to understand the nature of the relative motion of a human arm, films of the upper half of the human body were taken. These films help to define the parameters required for movement simulation. These parameters are movement trajectory, movement velocity, arm pressure applied on the lateral part of the trunk and the friction area. After creating the instrument, a set of soundtracks related to the noise generated by fabric-to-fabric friction was recorded. The recordings were treated with a specific software to extract the sound parameters and the acoustic imprints of fabric were obtained.
\end{abstract}

\section{Keywords:}

Fabric sound, Motion analysis, Frictional sound, Fabric

\section{Introduction}

Friction is an important physical phenomenon that has been studied for many decades. It was investigated in the studies of Amontons [1] in 1699 then by Coulomb [2] in 1781. Friction laws derived from their researches were empirical. At that time, surface state viewed in microscopic scale was not yet taken into consideration. In 1950, Bowden and Tabor [3] radically changed the classical laws of friction by developing asperitybased models of contact. Yokoi and Nakai [4] and Othman [5] revealed that the surface state of two objects in dynamic contact could induce basic acoustic frequencies. This new approach to friction was widely studied for rigid materials, that is, metal-to-metal friction, but rarely for flexible materials, that is, textile-to-textile friction.

In this study, we focus on the friction of fibre-based flexible materials and the noise generated by this friction is then analysed in order to identify a noise signature. Recently, Eunjou and Gilsoo [6], [7] designed an instrument that contributes to study the relationship between the structure and mechanical properties of different fabrics and their sound spectra. This spectrum is produced by fabrics' friction and contains information related to many properties of these materials. Changes in these properties could be revealed in changes in the sound spectrum produced. The same instrument was also used for the same purpose by other researchers: Gilsoo and al. [8], [9], Kim and Gilsoo [10], [11], and Youngjoo [12].

All of these researches were limited to a unidirectional linear trajectory. Usually, garments are either made of woven fabric, that is, warp threads are perpendicular to weft, or knitted fabrics where columns are perpendicular to rows. The fixed parameter, especially linear, form of movement trajectory adopted in the instrument previously developed does not properly mimic complex movement of a human wearing a textile garment.

For this purpose, we propose a new instrument that reproduces the real situation that includes all of these parameters by simulating the movement of a human arm in different conditions of motion: walking, jogging and running. It is expected that the instrument will provide a quantitative information of sound generated by the friction of fabrics. The results obtained will be beneficial in the development of sports clothing (hunting clothing for instance) as well as clothes for military purposes.

In this paper, first the mechanical description of motion simulator is described then the principle of the acquisition of the noise generated by the fabric friction is presented. The characteristics of the anechoic booth used to protect the developed instrument from external noises are also explained. Last, the signal treatment is detailed for one study case considering woven textile fabrics.

\section{Material and Methods}

\subsection{Motion Simulator}

To develop a motion simulator that reproduces human's mechanism and motion patterns, we have to analyse arm velocity, friction area, trajectory, and arm pressure. Basic ideas came from the research of Pontzer [13] and Collins [14]. conducted on the role of the swivel motion of the human arm 
on the body equilibrium in activity by video analysis methods used in sport performance analysis [15]. For this study, human volunteers, a treadmill and a camera were used.

The treadmill allowed to create three modes of motion, that is, walking, jogging and running. The camera was used to film the upper half part of the human body and more precisely to study the relative motion of the arm. Two young male volunteers were selected from the same age range (29 and 30 years old) with a very close match in their height (177 and $176 \mathrm{~cm}$ in height) and in their weight ( 75 and $77 \mathrm{~kg}$ ). Subjects gave their informed consent prior to participation. Both of them conducted a series of six trials in each of the three modes. The walking speed, jogging speed and running speed were fixed, respectively, to $2 \mathrm{~km} / \mathrm{h}, 7 \mathrm{~km} / \mathrm{h}$ and $9 \mathrm{~km} / \mathrm{h}$.

To define the contact area of the friction of the arm against the body, a simple paint on the inner arm of the volunteers was used. During motion, the paint was transferred to the garment. The position and area of the friction surface was identified thanks to image processing software [16]. To measure the pressure applied during the effort, a pressure sensor (Flexi force sensor type A401) [17] was placed on their garment (a T-Shirt). The sensor's signals were captured during the experiments and analysed by using the software LabVIEW of National Instruments (NI) [18].The position and friction surface, the pressure applied during the movement has been considered for the average values obtained for the two volunteers.

\subsection{Friction Sound Recording}

A Brüel \& Kjaer $1 / 2$ inch type free-field microphone (type 4133) was attached to a height-adjustable support placed for detecting the friction noise of fabric specimens. This microphone was positioned close to the sample $(1 \mathrm{~cm})$. The sound recording was performed with a Sony recorder type (PCM-M10) connected to a Brüel \& Kjaer type (2606) amplifier. The chain of measurement (microphone, amplifier, and recorder) has been calibrated at $700 \mathrm{mV} / \mathrm{Pa}$.

The duration of a recording was about $10 \mathrm{~s}$, with a sampling frequency of $96 \mathrm{kHz}$. The raw sound was processed by Audacity Software [19] and sequences of a few seconds [0.5 $\mathrm{s}$ to $1 \mathrm{~s}$ ] were taken for the final treatments. Noise levels in $\mathrm{dB}$ and $d B(A)$ are obtained and analysed by third octave from which acoustic imprints are deduced.

\subsection{Fabric Specimen}

Samples of fabrics currently used for sports garment were used in our experiments. Tests were performed in a standard atmosphere for textile testing $(65 \pm 4 \%$ Relative Humidity and $20 \pm 2^{\circ} \mathrm{C}$ ) [20]. Samples were conditioned 24 hours before being tested. The characteristics of samples are presented in Table 1.

\section{Results and discussion}

\subsection{Determination of Motion Range and Arm Velocity}

Different locations of the arm position were marked. The position of the markers can be seen in Figure 1. These markers were used as references to calculate the moving speed of the arm.

Figure 2 exposes steps of arm relative motion calculations.

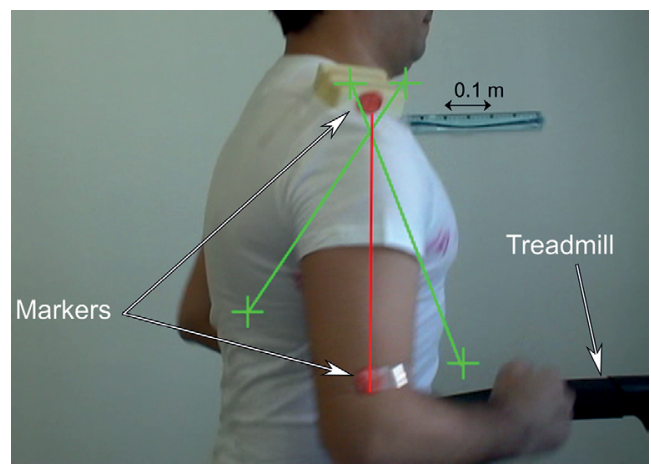

Figure 1. Volunteer in walking mode and markers position

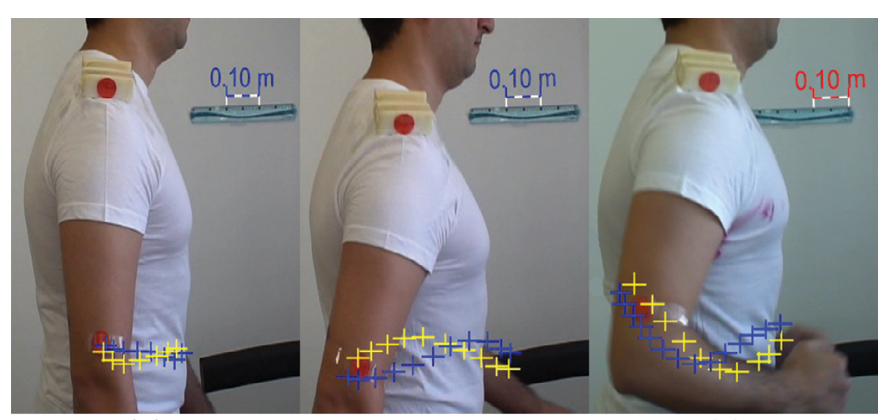

(a) (c)

Figure 2. Motion trajectory (a) walking; (b) jogging; (c) running.

Table 1. Sample's characteristics

\begin{tabular}{|c|c|c|c|c|c|c|c|}
\hline $\begin{array}{c}\text { Sample } \\
\mathbf{N}^{\circ}\end{array}$ & Material & $\begin{array}{c}\text { Weave } \\
\text { pattern }\end{array}$ & $\begin{array}{c}\text { Number of } \\
\text { yarn/cm } \\
\text { Warp } \\
\text { direction }\end{array}$ & $\begin{array}{c}\text { Number of } \\
\text { yarn/cm } \\
\text { Weft } \\
\text { direction }\end{array}$ & $\begin{array}{c}\text { Yarn count } \\
\text { Warp } \\
\text { direction } \\
{[\text { [Tex }]^{*}}\end{array}$ & $\begin{array}{c}\text { Yarn count } \\
\text { Weft direction } \\
{[\text { [Tex }]^{*}}\end{array}$ & $\begin{array}{c}\text { Fabric } \\
\text { Weight } \\
{\left[\mathbf{g}^{*} \mathbf{m}^{2}\right]}\end{array}$ \\
\hline 1 & $\begin{array}{c}\text { Polyamide / } \\
\text { Polyurethane }\end{array}$ & Plain & 41 & 23 & 6 & 20 \\
\hline 2 & $\begin{array}{c}\text { Cotton / } \\
\text { Spandex }\end{array}$ & Plain & 85 & 40 & 7 & 10 \\
\hline
\end{tabular}


Speeds of the arm movements have been evaluated for the three conditions described earlier (walking, jogging and running) and the results are shown in Table 2. Six replicates (R1 to R6) have been performed.

As expected, arm swing, which is critical for maintaining stability, is increasing as velocity is increasing.

\section{$\underline{3.2 \text { Identification of the Friction Area }}$}

The position and area of the friction surface has been identified with the help of the paint as shown in Figure 3 . The results of the six replicates (S1 to $\mathrm{S} 6$ ) and of the average surface area are presented in Table 3.
A surface of $90 \mathrm{~cm}^{2}$ was chosen for the motion simulator.

\subsection{Identification of the Pressure}

A pressure sensor FlexiForce type (A401) with a circular sensing area of $25.4 \mathrm{~mm}$ in diameter and thickness of 0.21 $\mathrm{mm}$ was used. A calibration curve has first been set up using increasing test weights and plotting obtained voltage, as shown in Figure 4.

The sensor was placed on the garment at the centre of the previously determined friction area as shown in Figure 5. To ensure a good contact of the sensor on the fabric, it has been firmly glued. Connectors were located along the side seams of the garment.

Table 2. Speeds of arm movement

\begin{tabular}{|c|c|c|c|c|c|c|c|c|}
\hline $\begin{array}{c}\text { Speed } \\
{[\mathrm{m} / \mathrm{s}]}\end{array}$ & R1 & R2 & R3 & R4 & R5 & R6 & Mean & CV\% \\
\hline Walking & 0.53 & 0.62 & 0.59 & 0.49 & 0.56 & 0.58 & 0.561 & 7.51 \\
\hline Jogging & 0.99 & 0.96 & 0.88 & 0.93 & 0.9 & 0.98 & 0.94 & 4.30 \\
\hline Running & 1.68 & 1.65 & 1.64 & 1.62 & 1.63 & 1.67 & 1.649 & 1.24 \\
\hline
\end{tabular}

Table 3. Friction area between arm and trunk

\begin{tabular}{|c|c|c|c|c|c|c|c|c|}
\hline Area $\left[\mathrm{m}^{2}\right]$ & S1 & S2 & S3 & S4 & S5 & S6 & Mean & CV\% \\
\hline Walking & 0.0075 & 0.0083 & 0.0079 & 0.008 & 0.0096 & 0.01 & 0.0085 & 10.8 \\
\hline Jogging & 0.0116 & 0.0116 & 0.012 & 0.0121 & 0.0132 & 0.0133 & 0.0123 & 5.7 \\
\hline Running & 0.0156 & 0.0158 & 0.016 & 0.0162 & 0.018 & 0.0184 & 0.0166 & 6.6 \\
\hline
\end{tabular}

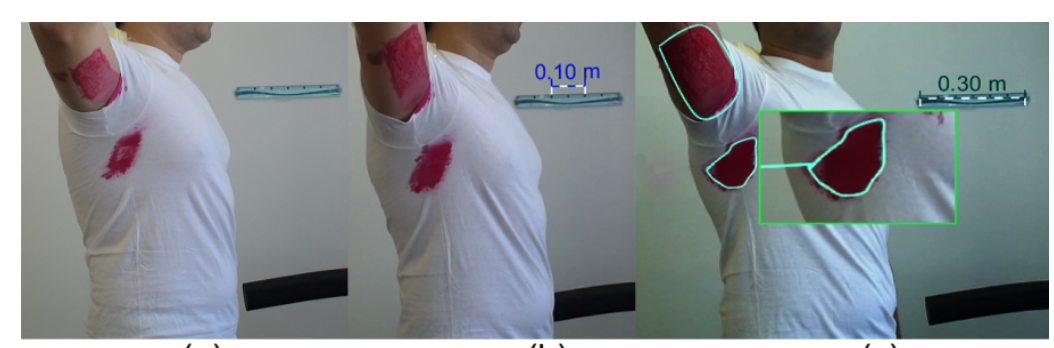

(a)

(b)

(c)

Figure 3. Imprint of friction area (a) walking, (b) jogging, (c) running.

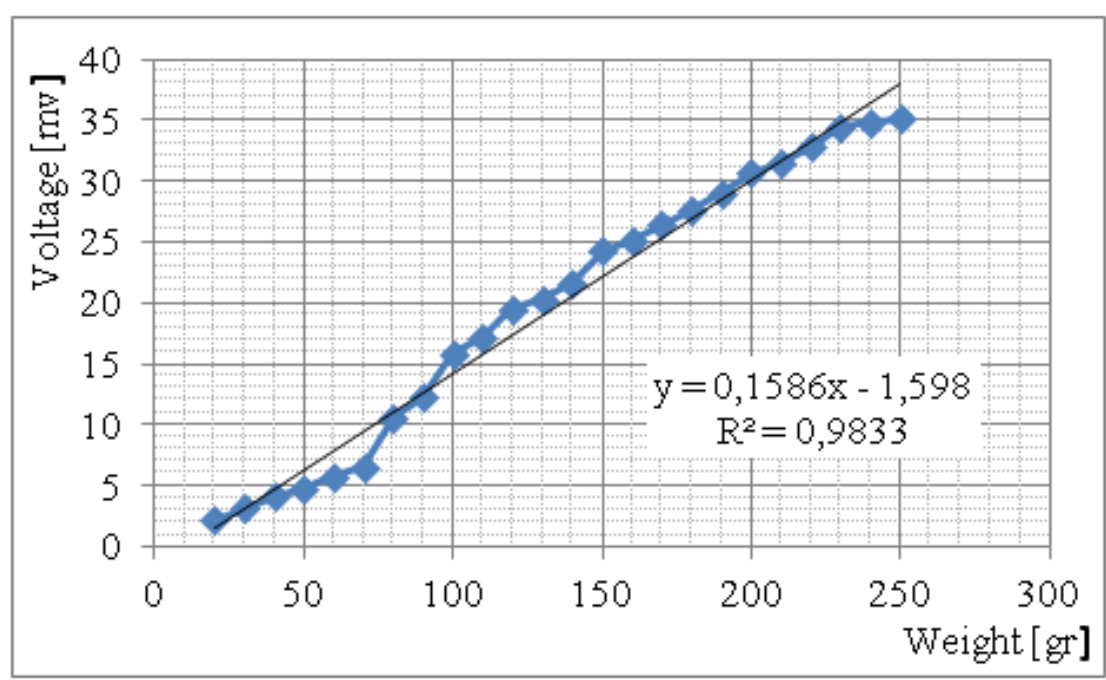

Figure 4. Sensor calibration curve 


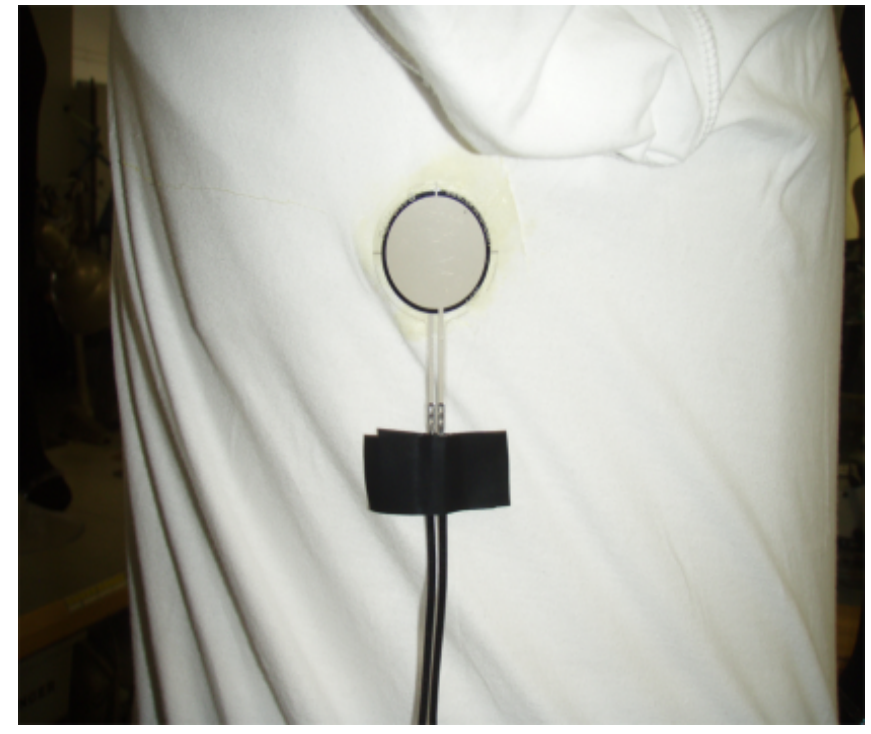

Figure 5. Pressure sensor on the garment

Using the sensor calibration curve, pressures applied on friction area during the three test modes (walking, jogging and running) have been obtained. Results are presented in Table 4. It can be observed that, the pressure was increasing with the velocity.

Table 4. Results of friction pressure

\begin{tabular}{|c|c|c|c|}
\hline Mode & $\begin{array}{l}\text { Walking } \\
(2 \mathrm{~km} / \mathrm{h})\end{array}$ & $\begin{array}{l}\text { Jogging } \\
(7 \mathrm{~km} / \mathrm{h})\end{array}$ & $\begin{array}{l}\text { Running } \\
(9 \mathrm{~km} / \mathrm{h})\end{array}$ \\
\hline $\begin{array}{c}\text { Average } \\
\text { voltage } \\
{[\mathrm{mV}]}\end{array}$ & 12.3 & 18.4 & 31.0 \\
\hline $\begin{array}{c}\text { Pressure } \\
\text { [KPa] }\end{array}$ & 16.7 & 23.5 & 38.5 \\
\hline
\end{tabular}

\subsection{Design and Mechanical Manufacturing of the Prototype Instrument}

The technical specification for the design of this new instrument of measure was:

- Movement of the mobile sample holder similar to the movement of the human arm,

- Simplicity of positioning and attachment of the fabric specimen, - Removable and adjustable microphone and sample holder,

- Insulation of the dragging area from the mechanical part,

- Silent mechanical movement,

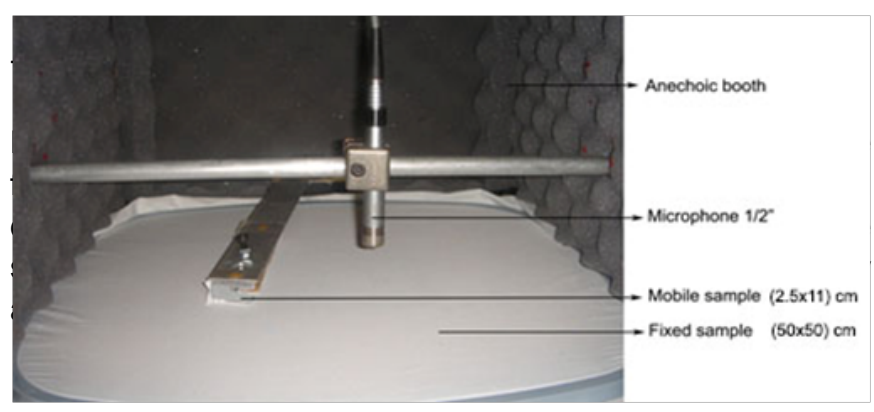

Figure 6. Fabric-to-fabric friction

The motion is given by a DC electric motor (5) thanks to a mechanical part that generates the swing of the mobile sample (11). Length of the metallic plate bar (10) and dimension of the rotating parts as well as the motor speed were calculated according with the results obtained in term of surface and speed previously mentioned.

Mobile (3) and fixed holders (4) with fabric specimens submitted to friction and microphone were placed inside of

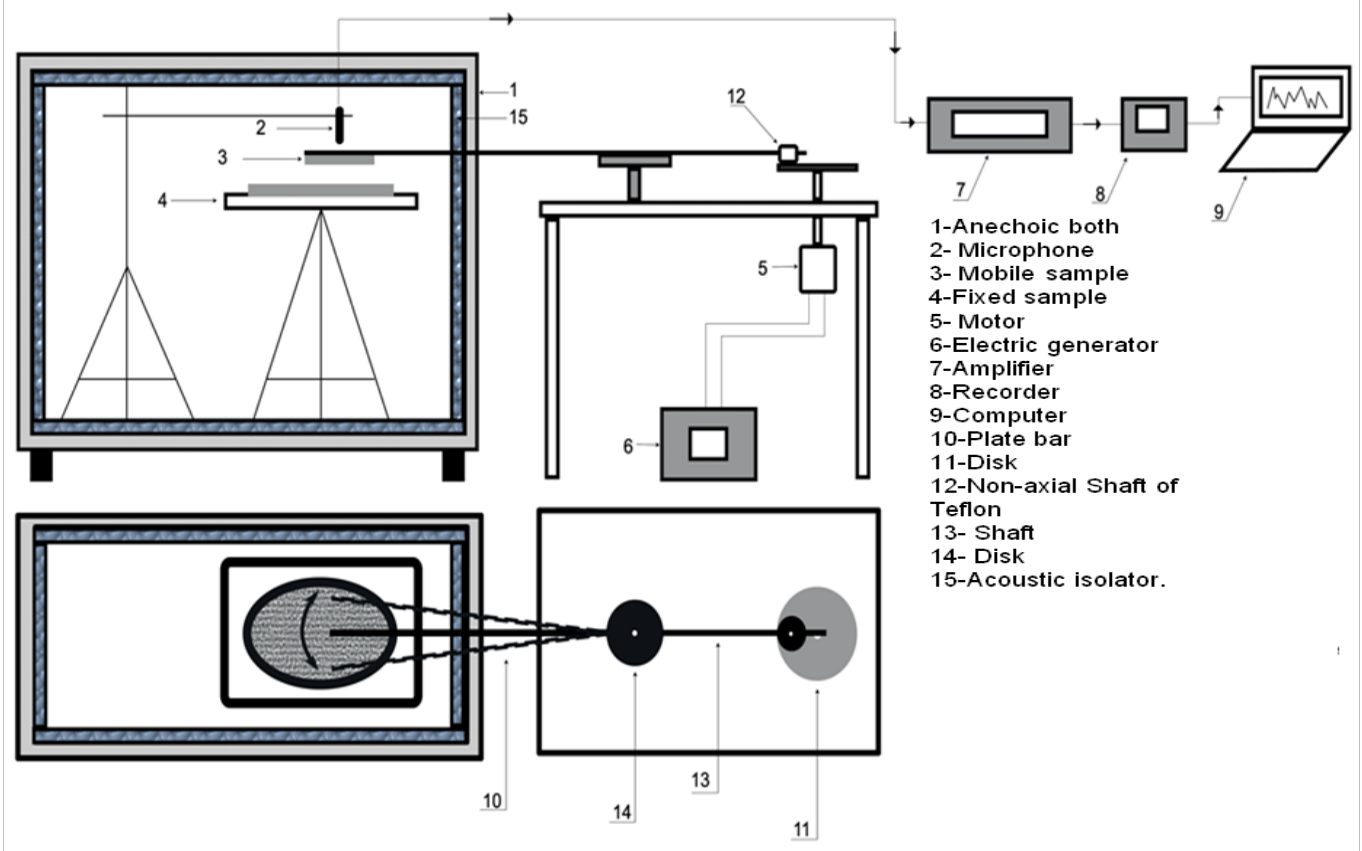

Figure 7. Instrument for frictional sound analysis 
an anechoic booth (1), whereas mechanical parts of motion simulator, recorder and amplifier were placed outside to prevent external local sounds from interfering with fabric friction noise. Reduction of noise of the mechanical parts has been obtained by balancing moving parts, lubrication, ensuring that machine rotational speeds do not coincide with resonance frequencies of the structure, etc.

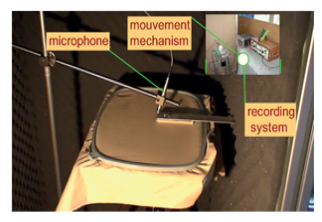

Sample part inside anechoic booth

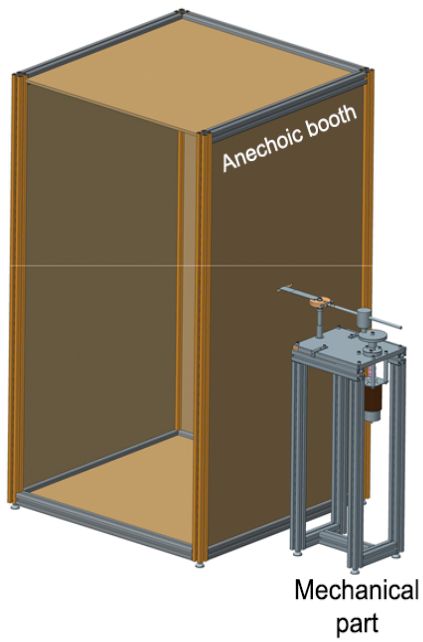

Figure 8. Lateral view of the developed instrument

The anechoic booth consists of an echo-free enclosure with walls, ceiling and floor covered in a highly sound absorptive material (foam) to eliminate any reflections. The attenuation of the developed anechoic booth was estimated in a reverberant chamber. This room is instrumented with eight loudspeakers (two subwoofers, two boxes for medium frequency range $200 \mathrm{~Hz}-800 \mathrm{~Hz}$ and 4-speaker horns for high frequencies). In this room the sound field is diffuse.

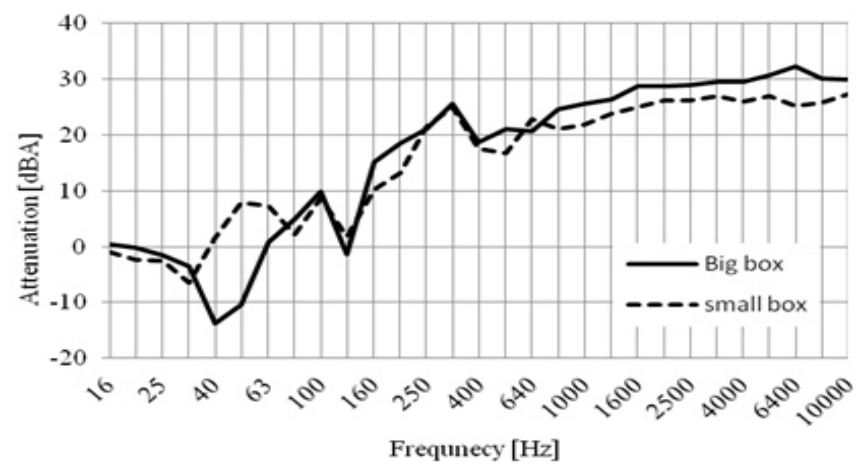

Figure 9. Attenuation of the 2 anechoic booths

The volume of the large box tends to shift its resonance towards the lower frequencies revealing better attenuation as compared with the small box.

\subsection{Experiment with Fabric Specimens}

Two samples of the same fabric have been used for each test. A first sample of fabric $\left(50 \times 50 \mathrm{~cm}^{2}\right)$ was attached to the fixed sample holder, and another sample of the same fabric $\left(2.5 \times 11 \mathrm{~cm}^{2}\right)$ was attached to the mobile sample holder. The two samples of the same fabric have been rubbed each against other. The friction is neither in the weft direction nor in the warp direction only, but it is in swing movement (figure 10). This experiment has been carried out with the identified frictional velocity and pressure applied at walking, that is, 0.56 $\mathrm{m} / \mathrm{s}$ and $16.7 \mathrm{kPa}$. The sound data have been collected and stored as sound files. A computation program for the graphical representation of the sound data analysis has been developed and used to extract the acoustic imprints of the generated noises. By using this computer program, the data analysis of our experiment was performed.

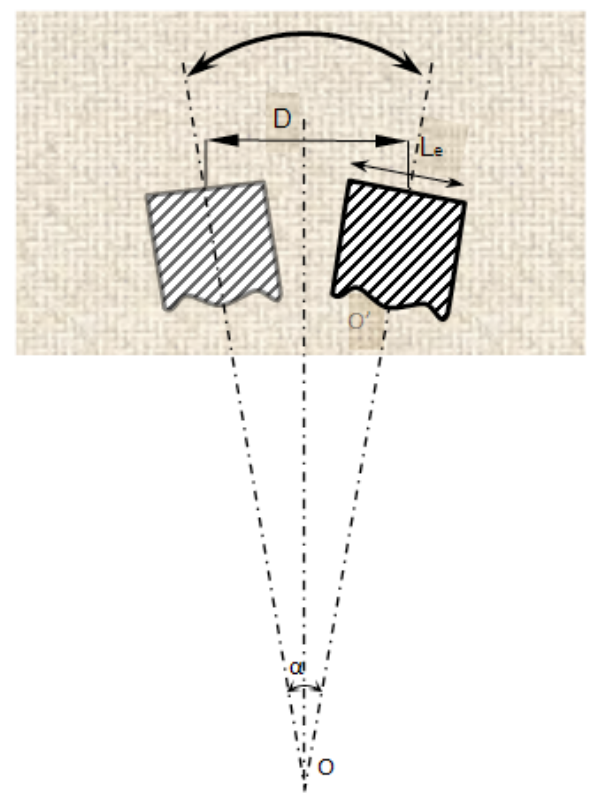

Figure 10. Swing motion of the mobile sample holder

Where:

oo': scan axis, $\mathrm{L}_{\mathrm{e}}$ : wide of mobile sample holder, $\mathrm{D}$ : maximum width scanning of the axis oo', $\alpha$ : angle of scanning $\left(18^{\circ}\right)$.

\subsection{Sound Spectra of Sample According to Arm Movement}

Acoustic imprint of sample 1 and sample 2 are presented in Figures 11 and 12 . In order to ensure the repeatability of the measurement, friction tests have been performed five times for the same sample in the same conditions. Results are presented in figure 13 for sample 1 after time-frequency analysis.

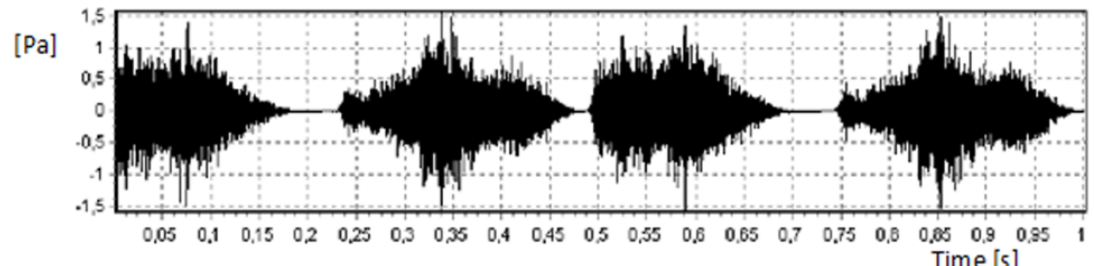

Figure 11. Acoustic imprint of sample 1 


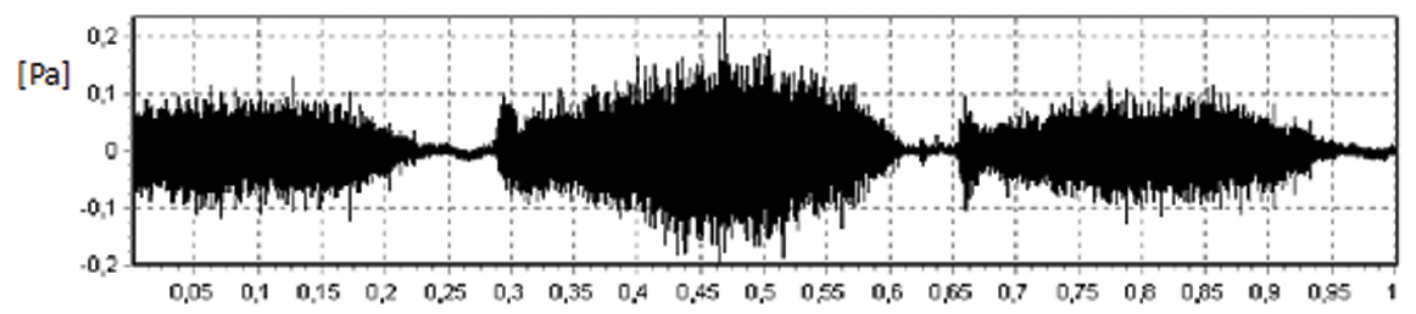

Time [s]

Figure 12. Acoustic imprint of sample 2

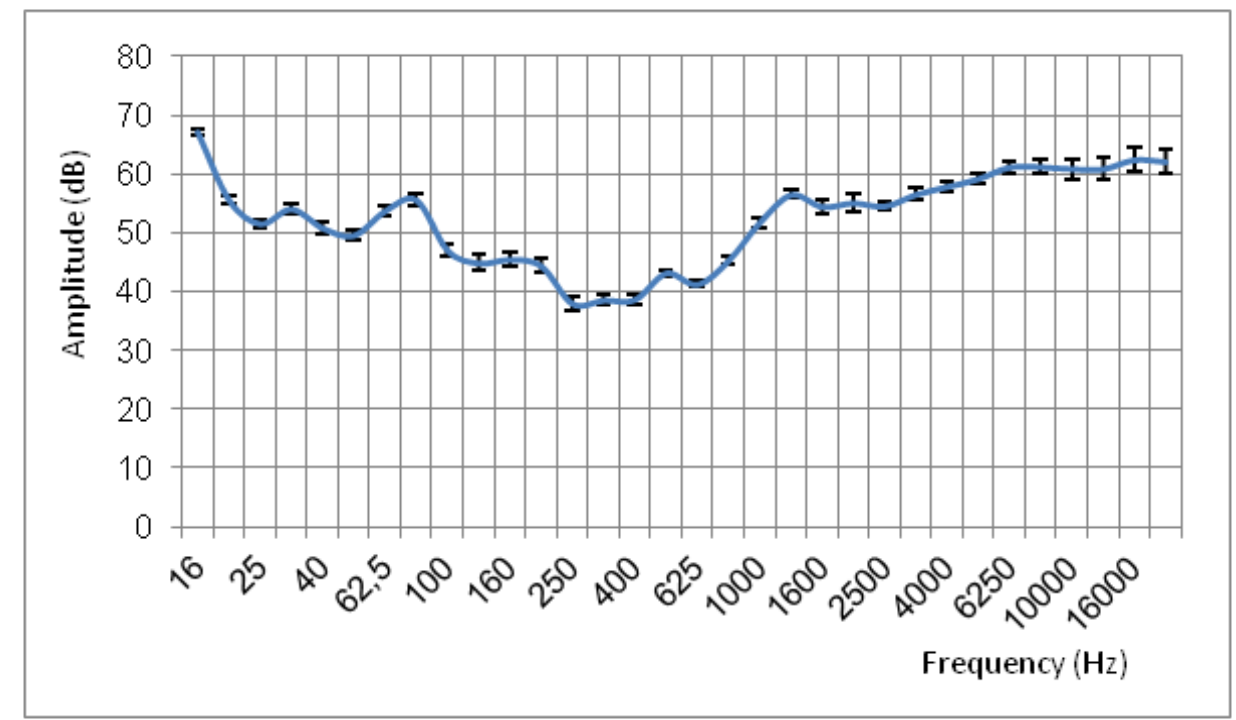

Figure 13. Average spectra of 5 replicates for sample 1 (polyamide/polyurethane)

Obtained data show good repeatability results and allow confirming mechanical performance of the instrument in terms of stability and precision.

Even if friction sounds are recorded inside the anechoic chamber, background noise that is mainly due to the noise of moving mechanical parts of the instrument transmitted through the openings of the booth has to be taken into account. In order to analyse its contribution and further analysed noise due to fabrics only, background noise of the instrument operating without fabric sample was measured. Obtained result is shown in Figure 14.

Sound signals for background and for both fabric samples have been treated by FFT. FFT allowed estimating the third octave band at frequencies ranging from $32 \mathrm{~Hz}$ to $20 \mathrm{kHz}$ that are applied to each of the data blocks (Figure 15). This figure shows that the background noise is low frequency noise. In order to attenuate the background noise on the friction sound signal, these signals (sample 1 and sample 2) have been filtered by high pass filter.

From these data, comparisons of acoustic spectral shapes are done in $\mathrm{dB}$ (Figure 15) and $\mathrm{dBA}$ (Figure 16). Imprints are obviously different. Sample 1 (polyamide/polyurethane) is more noisy and presents a frictional sound louder than Sample 2 (cotton/spandex) for all the range of frequency.

It can be observed that in the low frequency range, the sound signal is mainly caused by the background noise of the mechanism of the instrument. Consequently, background noises, still present in the imprints of the two fabrics, do not significantly affect the perceived signals.

[Pa]

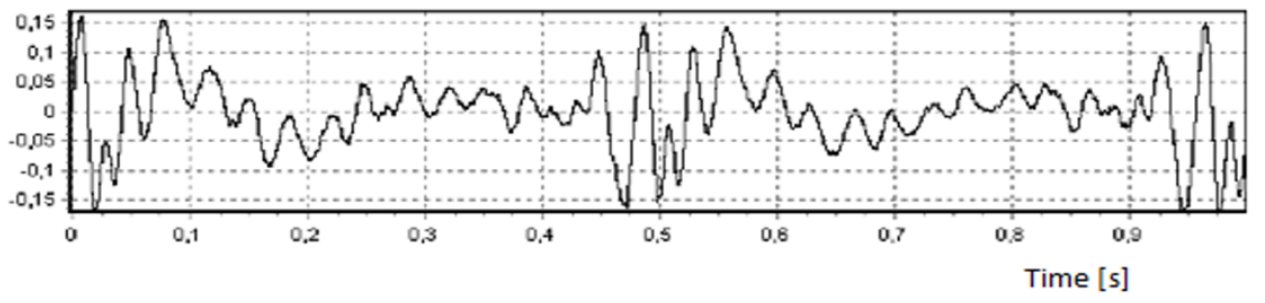

Figure 14. Background noise 


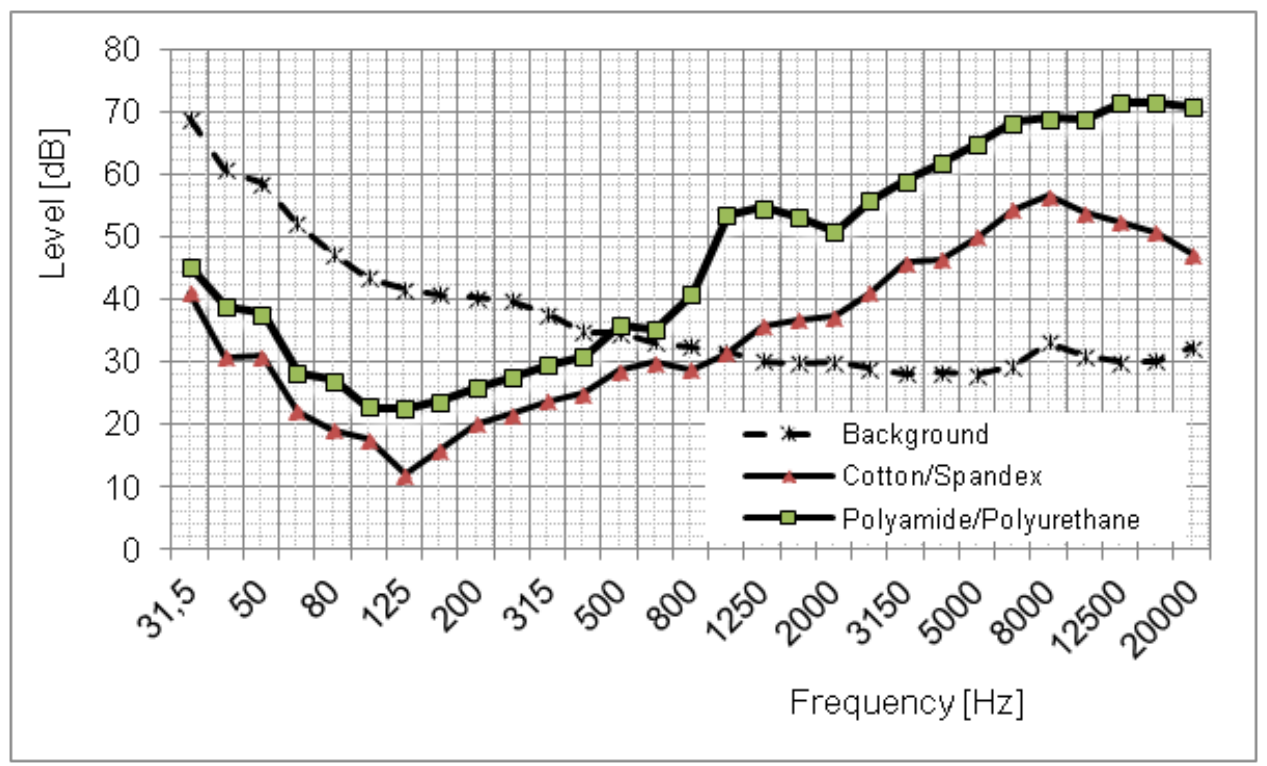

Figure 15. Comparison of both fabric samples in $\mathrm{dB}$

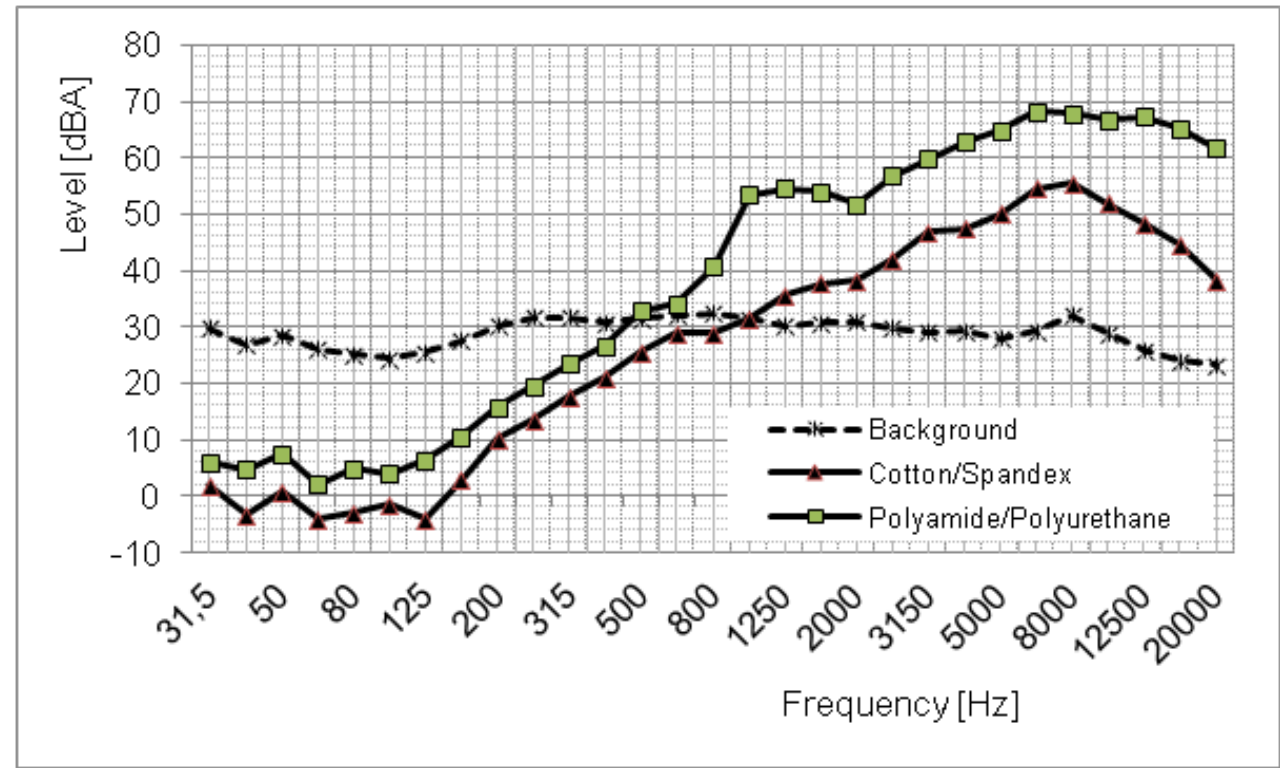

Figure 16. Comparison of both samples in $d B(A)$

Sound produced by fabric friction is affected by parameters such as pattern, yarn count, surface roughness, yarn thickness, hairiness, etc., but also physical or chemical treatments applied on textile fabrics. From the results obtained with two different fabrics commonly used for sport activities, with the same pattern (plain pattern) but made of different materials and having different structure parameters tested with the newly developed instrument, it can be observed that significant differences are found when measuring the sound produced by friction produced with the developed instrument.

\section{CONCLUSION}

This study has led us to develop an instrument able to simulate the friction of garment in wear condition according to specific human activities. The machine parameters, that is, speed, contact area and applied pressure, are adjustable. The precise conditions allow extracting sounds produced by fabric/fabric friction. Fabric sound level, which is the factor that influences the unpleasantness or pleasantness of sound of particular fabrics, can be recorded, and then objectively compared or optimised. A trained panel will later perform sensory evaluation of the frictional sounds of the same fabrics in order to correlate obtained data with sensory feelings.

\section{REFERENCES}

[1] Amontons, G., Les frottements des machines, Histoire de l'Académie Royale des Sciences, Paris, 1699.

[2] Coulomb, C. A., Théorie des machines simples, Mémoire de mathématique et de physique de l'académie royale des Sciences, Paris, 1781.

[3] Bowden, F.P., and Tabor, D., the Friction and Lubrication of Solids. Oxford university press, 1950.

[4] Yokoi, M., and Nakai, M., The influence of random surface roughness on frictional noise. Japan Society of Mechanical Engineers 25: 827-833 (1982).

[5] Othman, M.O., and al. Experimental investigation of frictional noise and surface-roughness characteristics. Experimental mechanics 30(4): 328-331 (1990). 
[6] Eunjou, Y., Gilsoo, C., Fabric Sound parameters and their relationship with mechanical properties. Textile Research Journal 70(9): 828-836 (2000).

[7] Eunjou, Y., Gilsoo, C., A Fabric Sound Evaluation System for Totally Auditory Sensible Textiles. Textile Research Journal 72(7): 638-644 (2002).

[8] Gilsoo, C., Jayoung, C., Chunjeong, K., and Jiyoung, $H$., Physiological and Subjective Evaluation of Rustling Sounds of Polyester Warp Knitted Fabrics. Textile Research Journal 75(4): 312-318 (2005).

[9] Gilsoo, C., and al. Effect of Fabric Sound and Touch on Human Subjective Sensation. Fibers and Polymers 02(04): 196-202 (2001).

[10] Kim, C., Gilsoo, C., Effects of Basic Weave Differences in Silk Fabric and Yarn Type Variations in Satin Weave on Sound Parameters. Textile Research Journal 72(6): 555560 (2002).

[11] Kim, C., Gilsoo, C., Characteristics of Rustling Sound Created by the Structure of Polyester Warp Knitted Fabrics. Textile Research Journal 73(8): 685-691 (2003).
[12] Youngjoo, N., Variations in Sensibility to Fabric Frictional Sound by Fiber Type and Subject. Textile Research Journal 73(9): 837-842 (2003).

[13] Pontzer, H., Holloway, J.H., Raichlen, D.A., Lieberman, $D . E$. Control and function of arm swing in human walking and running. Journal of Experimental Biology 212(4): 523534 (2009).

[14] Collins, S.H., Adamczyk, G.P., Kuo, D.A., Dynamic arm swinging in human walking. Proceedings of the Royal Society B: Biological Sciences 276 (1673): 3679-3688 (2009).

[15] http://www.dartfish.com/fr/

[16] http://inkscape.org.

[17] http://www.tekscan.com/flexible-force-sensors.

[18] Software LabVIEW of National Instruments (NI).

[19] http://audacity.sourceforge.net/

[20] Textiles. Standard atmospheres for conditioning and testing. ISO139 ( 2005 ). 